\title{
AVALIAÇÃO E DIAGNÓSTICO DO PROCESSO DE REINSERÇÃO FAMILIAR E SOCIAL DE CRIANÇAS E ADOLESCENTES EGRESSOS DE UMA CASA DE PASSAGEM
}

[Evaluation and diagnosis of children and adolescents' process of family and social reintegration ex-inmates in a temporary shelter]

Mara Regina Santos da Silva* Karina da Silva Nunes**

RESUMO: A reinserção familiar e social de crianças e adolescentes afastados de suas famílias e institucionalizadas devido a maus tratos é um desafio de proporções significativas. Este estudo objetiva fazer a avaliação e o diagnóstico da situação social e familiar atual dos egressos de uma instituição destinada ao abrigo temporário desses jovens, localizada no sul do Brasil. Os sujeitos são as famílias que participaram de um programa de reinserção familiar desenvolvido por esta casa de passagem, durante o período em que seus filhos estiveram abrigados. Os dados foram colhidos através de entrevista e questionário. Os resultados retratam a situação destas famílias em termos de inserção de seus membros no mercado de trabalho e na vida escolar; interações familiares; principais fatores que influenciam favorável e/ou desfavorávelmente no processo de reinserção que estão vivenciando. São discutidos alguns desafios envolvidos no processo de reinserção familiar e social de egressos das casa de passagem.

PALAVRAS-CHAVE: Enfermagem; Família; Violações dos direitos humanos.

\section{INTRODUÇÃO}

A infância vítima de maus tratos compreende o contingente de crianças e adolescentes que, de

\footnotetext{
*Enfermeira. Professora de Enfermagem em Saúde Mental da Fundação Universidade Federal do Rio Grande. Doutora em Enfermagem.

${ }^{* *}$ Acadêmica do Curso de Enfermagem da Fundação Universidade

Federal do Rio Grande. Bolsista de Iniciação Científica

- PIBIC
}

forma quotidiana, são violados em seus direitos de ser humano e de cidadãos, seja por omissão e/ ou transgressão da família, da sociedade ou do Estado (Azevedo; Guerra, 1993). São pessoas vivendo em condições de risco psicossocial, expostas às mais variadas modalidades de violação, incluindo o abuso físico, sexual, psicológico e a negligência, entre outros. Essas crianças/adolescentes são aquelas que não conseguiram, ainda, se beneficiar do Estatuto da Criança e do Adolescente (ECA) o qual, em seus princípios fundamentais, preconiza a proteção contra qualquer forma de negligência, crueldade e exploração, além de oportunidades e facilidades a fim de facultar seu desenvolvimento físico, mental, moral, espiritual e social, de forma sadia e em condições de liberdade e dignidade. Por diferentes razões, elas estão excluídas da proteção especial preconizada neste documento, pois, mesmo tendo seus direitos regulamentados, continuam sendo vítimas do comportamento perverso dos adultos, seja porque muitas nem mesmo chegam a ser consideradas e respeitadas como seres humanos, ou porque são rejeitadas e apenas toleradas pelo sistema social que as produz, ao mesmo tempo que as exclui.

Embora os maus tratos contra crianças e adolescentes seja um problema tão antigo quanto o mundo, uma definição operacional efetiva para esse termo ainda esbarra na falta de concenso acerca, por exemplo, dos parâmetros utilizados para determinar o que seja um comportamento parental inaceitável ou perigoso. Apesar disso, é indiscutível a necessidade de estabelecer uma 
linguagem comum, de tal forma a viabilizar a comunicação entre os diferentes campos em que este problema transita (legal, clínico, e outros).

Neste estudo, consideramos quatro modalidades de maus tratos infantis referidas por Cicchetti e Lynch (1995), as quais levam em conta a natureza da experiência que os sujeitos estão expostos. A primeira, é o abuso físico, entendido como o ato através do qual um adulto provoca dano corporal ou enfermidade, de caráter não acidental a uma outra pessoa. A segunda, abuso sexual, é a denominação atribuída ao contato sexual, ou tentativa de contato, de um adulto para uma criança ou um adolescente com o propósito de obter gratificação sexual ou benefícios financeiros. A terceira, refere-se ao abuso psicológico considerado como a interferência negativa do adulto sobre a criança e sua competência social, conformando um padrão de comportamento destrutivo, o qual pode ser observado através de atitudes como rejeitar: quando o adulto não aceita a criança e deprecia seu valor e suas necessidades; isolar: o adulto afasta a criança ou o adolescente de experiências sociais habituais à sua idade, impedindo-o de ter amigos e fazendo crer que ela/ele está só no mundo; aterrorizar: o agressor instaura clima de medo, agride verbalmente a criança, atemoriza-a e a faz acreditar que o mundo é hostil; ignorar. o adulto não estimula o crescimento emocional e intelectual da criança ou do adolescente; corromper: o adulto induz a criança ou adolescente à prostituição, ao crime, ao uso de drogas.

A quarta modalidade de maus tratos referese a negligência, a qual é considerada pelos autores como o fracasso em prover os cuidados mínimos necessários a uma criança, quanto a ausência ou insuficiência de supervisão adequada por parte do adulto. Na prática, a negligência se traduz em não cuidar da criança, não prestar atenção às suas necessidades, seus desejos, colocando-a, freqüentemente, em segundo plano. Trata-se de uma interação entre pais e filhos que, segundo Manciaux (1996), pode produzir efeitos negativos significativos sobre o desenvolvimento da criança decorrentes do fato de esta ser pouco estimulada.

Sluzki (1996) chama atenção que, frequentemente, os maus tratos constituem uma violação praticada por aqueles que têm a responsabilidade afetiva, social e legal de cuidar da criança e do adolescente, de manter a ordem em seu mundo, de preservar a estabilidade e previsibilidade em suas vidas, ou seja: o Estado e a família que deveriam ser fontes de proteção comportam-se como fontes de terror. Especificamente no que se refere a família, esta transformação do caráter protetor em caráter violento geralmente ocorre em um contexto enganoso, no qual os significados são falseados e sustentam um discurso que nega esta transformação, a tal ponto que alguns pais justificam a violência física como meio de educar os filhos e o abuso sexual como uma forma de amor familiar. Para enfrentar esse problema, vários programas e serviços de proteção à infância/ adolescência são desenvolvidos no Brasil, alguns implantados e mantidos através de ação governamental, outros por iniciativa nãogovernamental. Em sua maioria, esses serviços se organizam tomando como referência os preceitos do ECA e tentam trabalhar no sentido da reinserção familiar dos jovens que abrigam, geralmente encaminhados a partir dos Conselhos Tutelares (SILVA, 2003).

Dentre esses programas, está o Projeto Sentinela, lançado pelo governo federal em parceria com os municípios, destinado a cumprir as linhas de ação da política de atendimento estabelecido no artigo 86 do Estatuto da Criança e do Adolescente. Trata-se de um projeto que está sendo implantado nas regiões metropolitanas brasileiras, inseridas no Programa Nacional de Segurança Pública, em grandes entroncamentos rodoviários, pólos turísticos, pólos industriais, zonas de garimpos, áreas portuárias e, ainda, em lugares que comprovem situações de violência contra crianças e adolescentes. Dentre seus objetivos prioriza: construir, nos municípios, uma rede de serviços que permita a garantia dos direitos fundamentais da criança e dos adolescentes; desenvolver ações sociais para o fortalecimento da auto-estima e o restabelecimento do direito a convivência familiar e comunitária da população infanto-juvenil; proporcionar a inclusão da clientela atendida pelo Programa (crianças e adolescentes até 18 anos incompletos, vítimas de maus tratos e suas famílias), em serviços prestados pelas instituições sociais sediadas na cidade.

Outros programas de reinserção familiar e 
social além deste, são desenvolvidos em diversas regiões do país, a maioria tendo como meta abrigar, proteger e resgatar a convivência e os vínculos entre os jovens abrigados e suas famílias. Entretanto, apesar de estabelecerem esta prioridade, nem sempre esses programas conseguem dar apoio às famílias e garantir a continuidade do processo de reinserção após o jovem ser desligado da instituição. Geralmente, a partir deste momento ocorre uma interrupção nesse processo deixando evidente a existência de uma fragilidade significativa nos programas de reinserção familiar e social.

O retorno à família é, sem dúvida, uma etapa muito delicada quando se trata de reinserção de jovens em situação de maus tratos, uma vez que lá, geralmente, permanecem vivos muitos dos problemas que contribuíram para a institucionalização e o rompimento dos vínculos familiares. Apesar desta importância, é justamente nesta etapa que o acompanhamento dos profissionais e o suporte técnico para todos os envolvidos nesta situação é interrompido, muitas vezes, por falta de recursos materiais e humanos para dar continuidade ao programa ou, não raro, por falta de conscientização da importância desse momento para a efetivação do processo de reinserção. Esta lacuna que se institui evidencia que por detrás da criança/adolescente maltratada, geralmente está uma família desassistida pelos serviços de saúde e de ação social.

É importante destacar que esta ruptura no processo de reinserção pode ser suficiente para comprometer o futuro tanto destas crianças, quanto de suas famílias. Além disso, esses filhos estão vivendo uma fase de seu desenvolvimento (infância e adolescência) que, mesmo quando o contexto é satisfatório, já não é fácil para a família manejá-los e, mais difícil se torna, quando o ambiente é permeado de adversidades. Nesses casos, redobra a importância e a necessidade de suporte social à essas famílias já que este é um elemento essencial para que esses jovens tenham a chance de construir uma trajetória de vida normativa, apesar dos problemas que enfrentam.

Apesar de muitos estudos que vêm sendo desenvolvidos sobre o tema maus tratos na infância, principalmente nos últimos tempos, diversos autores apontam a necessidade, ainda, de aprofundar a compreensão acerca deste fenômeno perverso que atinge um contingente considerável da população jovem em todo o mundo, podendo comprometer seriamente seu futuro (Moraes, 1998; Cicchetti e Lynch (1995; Bringiotti, 1999). É preciso entender o que se passa com as pessoas que estão implicadas numa interação desse tipo, o que acontece com os pais, por exemplo, que sustenta esse tipo de interação com os filhos, invertendo a função de proteção atribuída à família e passando-a para a de agressora. Além disso, é preciso levar em conta que, segundo Bringiotti (1999), uma abordagem satisfatória deste problema requer o investimento sobre dois outros eixos fundamentais: a prevenção e a investigação sobre esse tema. Dada a natureza do fenômeno, a prevenção não visa apagar a história de vida das crianças e dos adolescentes envolvidos numa relação como esta mas, sim, proteger a criança/adolescente que está sendo mal tratada e tentar reduzir a possibilidade de reprodução deste problema na vida adulta e nas gerações futuras. Já a investigação visa obter dados contextualizados acerca da magnitude desse problema e das modalidades de maus tratos mais frequentes em uma determinada região. Da mesma forma, visa definir abordagens adequadas para enfrentar este problema, assim como detectar fatores de risco e de proteção que influenciam e contribuem para perpetuar essa situação.

\section{OBJETIVO}

Uma vez que o enfrentamento do problema infância maltratada é, não apenas um compromisso ético de toda a sociedade, mas, também, uma condição imprescindível para que se possa avançar no sentido de preservar e promover a saúde e o desenvolvimento das pessoas e das famílias que vivenciam esse problema, desenvolvemos este estudo com o objetivo de "fazer avaliação e diagnóstico da situação social e familiar atual das crianças e dos adolescentes egressos de uma casa de passagem localizada no sul do Brasil"

De forma específica, investigamos: a inserção dos membros da família no mercado de trabalho; a inserção das crianças e dos adolescentes na vida escolar; as interações 
familiares; os fatores que estão influenciando, de forma favorável ou desfavorável, no processo de reinserção familiar e social destes egressos.

Com este estudo, pretende-se uma aproximação cognitiva com a situação vivida pelas famílias que enfrentam o problema de maus tratos e a tentativa de reinserção familiar e social de seus filhos, levando em conta as características do contexto social e cultural da região onde vivem. Ao mesmo tempo, a partir desta aproximação, contribuir para apoiar o processo de reinserção familiar e social de crianças e adolescentes que, neste contexto, vivem em situação psicossocial semelhante.

\section{METODOLOGIA}

A população em estudo é constituída pelos dados provenientes de famílias com filhos na faixa etária de 9 a 18 anos, os quais estiveram institucionalizados pelo menos uma vez em uma casa de passagem existente em um município, no sul do Brasil, sendo, portanto, egressos desta instituição. Para constituir a amostra foram selecionadas 40 famílias, a partir dos registros existentes na instituição, as quais poderiam ser localizadas nos limites desse município e cujos filhos foram submetidos a abuso físico, sexual, psicológico e negligência, e afastados do convívio familiar, por decisão do juizado da infância e da adolescência e encaminhados a esta casa-abrigo.

Durante sua permanência nesta instituição, as crianças/adolescentes, juntamente com suas famílias, foram incluídos em um programa de reinserção familiar e social desenvolvido pela equipe técnica da instituição. Este programa inclui a tentativa de reconstrução dos vínculos familiares, através da reaproximação progressiva entre eles e suas famílias, com apoio e orientação da equipe técnica durante o período em que o jovem está na casa de passagem. Inicialmente, os primeiros contatos entre a criança/adolescente e sua família aconteceram na própria instituição. Posteriormente, os jovens foram liberados para ir ao domicílio da família e, gradativamente, foi aumentando o tempo de permanência no lar. Os pais (ou responsáveis) e os filhos recebiam atendimento individual e no grupo familiar antes e após cada visita.
Respeitados os preceitos éticos da Resolução 196/96 para pesquisa com seres humanos, os dados foram coletados, após a assinatura do consentimento livre e esclarecido, entre junho e dezembro de 2004, utilizando como instrumentos a entrevista semi estruturada e questionário, os quais foram aplicados aos membros da família que concordaram em participar deste estudo.

\section{RESULTADOS}

\subsection{Inserção dos membros da família no mercado de trabalho}

A maioria dos entrevistados, incluindo os egressos e demais membos de suas famílias, estão fora do mercado de trabalho e sem perspectivas de emprego a curto prazo. Dentre os egressos, apenas dois desempenhavam atividade remunerada em caráter regular, mas em situações desfavoráveis. Um deles está na condição de presidiário e trabalha no próprio presídio, obtendo, desta forma, o sustento de sua família. Outra egressa trabalha em uma casa noturna, de onde obtém o próprio sustento. Em ambas as situações, os egressos preservam o vínculo com a casa de passagem, visitando a equipe técnica frequentemente (no primeiro caso, quando está autorizado a saídas externas).

Dentre as demais famílias, a renda familiar provêm, de forma preponderante, da execução de atividades de natureza esporádica, sem vínculo empregatício e sem remuneração fixa. As mães geralmente desempenhando serviços domésticos do tipo diarista e os pais envolvidos com o recolhimento de material reciclável. Trata-se sem dúvida de uma condição que contribui, desfavoravelmente, para manter as famílias em uma situação de pobreza muitas vezes extrema e aumentar, consequentemente, a precariedade de suas condições de vida.

É importante registrar que, além dessas dificuldades no plano econômico, uma das queixas mais frequentes registrada pelos pais é que eles perdem o "controle" sobre os filhos, justamente a partir do momento em que saem para trabalhar deixando-os em casa, geralmente sozinhos, sem cuidados e sem supervisão. Nessas ocasiões, os filhos acabam agregando-se com outros colegas e passam a maior parte do tempo na rua, expostos a experiências negativas.

Nesse contexto, o emprego de caráter regular é referido como a necessidade prioritária 
de todas as famílias em estudo pois este lhes permitiria estabelecer uma certa previsibilidade em termos de sustento da família e, também, organizar-se para cuidar de suas crianças e adolescentes.

\subsection{Inserção das crianças e adolescentes na vida escolar}

Os resultados apontam que $57,7 \%$ dos egressos entrevistados não frequentam a escola e que $42,3 \%$ estão estudando embora estejam defasados em termos da idade e o grau de escolaridade em que se encontram, vivenciando dificuldades para se relacionar com colegas e professores, dificuldades para acompanhar o aprendizado e, consequentemente, desestimulados para o estudo. Alguns dos adolescentes incluídos no percentual que estão estudando são egressos da instituição, mas no momento da entrevista realizada para a coleta de dados deste estudo, já haviam sido institucionalizados novamente, e, sendo assim, estavam frequentando a escola apenas porque esta é uma norma da instituição. Habitualmente, enquanto estão vivendo na companhia da família, não vão à escola, embora sejam matriculados. Apenas uma egressa frequentava regularmente uma escola de modelo, tendo os custos cobertos com o suporte financeiro de uma tia com quem mora desde que foi desinstitucionalizada.

\subsection{Relações familiares}

Cada uma das famílias entrevistadas neste estudo tem sua história relacional construída de forma única, a partir das vivências compartilhadas, o que inviabiliza a possibilidade de estabelecer um padrão de relações, uma vez que, aparentemente, têm em comum, apenas o fato de serem protagonistas da situação de maus tratos contra crianças e adolescentes. Entretanto, são as relações familiares, com toda sua diversidade que aparecem como um dos fatores que mais fortemente determina os rumos do processo seja no sentido da reinserção familiar e social da criança/adolescente ou de sua reinstitucionalização, principalmente as relações de afeto e de cuidado entre seus membros.

Especialmente aqueles adolescentes com história de várias passagens pelas instituições existentes no município são procedentes de famílias numerosas, nas quais predominam as relações conflituosas entre seus membros, particularmente entre os pais e os filhos. A expressão de afeto entre o egresso e seus familiares são raras e quando acontecem se restringe a mãe e o filho. Da mesma forma, a preocupação com relação ao bem estar ou outros sentimentos que demonstrem ser a criança/ adolescente importante para alguém da família, foram raramente mencionados.

As brigas que acontecem no espaço físico reduzido da casa onde geralmente mora um número de pessoas maior do que comporta são também frueqüentes. A comunicação é dificil com perda progressiva da capacidade de diálogo entre os membros da família, sendo que os pais referem dificuldades para colocar limites em seus filhos que não os reconhecem como figuras de autoridade. Este é um dos aspectos referidos como crítico nas relações familiares e para o qual expressam sua necessidade de ajuda.

Principalmente quando o período de institucionalização foi prolongado, o retorno do egresso para o lar transforma-se em um momento extremamente delicado uma vez que o distanciamento e a interrupção da convivência diária faz com que a criança/adolescente seja, muitas vezes, percebido pelos demais membros da família como se fosse um estranho no ninho. Nessas circunstâncias "descobrem" que aquele que vivia fora de casa é irremediavelmente ${ }^{1}$ diferente dos demais. Algumas famílias referem que são tantas as diferenças entre o egresso e aqueles que permaneceram no lar que o diálogo entre eles, por mais útil que possa ser, não consegue superá-las, nem atenuá-las. Assim, as dificuldades de relacionamento são praticamente inevitáveis, levando os pais a referirem que "não basta discutir para se compreender".

Por outro lado, nem todas as famílias participantes deste estudo vivenciam conflitos relacionais como os descritos anteriormente. Entre aquelas em que a institucionalização dos filhos

\footnotetext{
3"Irremediavelmente" foi o termo encontrado pelas autoras que mais se aproxima das idéias e dos sentimentos expressos por alguns familiares, por ocasião da entrevista de coleta de dados.
} 
estava fortemente relacionada com dificuldades econômicas e a inexistência de uma rede de suporte social efetiva, observou-se que, em geral, os vínculos afetivos estavam preservados, apesar do afastamento da criança/adolescente durante o período em que permaneceu no abrigo de menores. Nestas situações, quando retorna ao lar o filho é "bem vindo", muitas vezes, representando um certo "alívio para os pais" embora contribua para exacerbar as dificuldades econômicas que, via de regra, são desencadeadoras de conflitos interpessoais.

A expressão, "cuidar bem dos filhos custa caro", utilizada por um pai traduz bem esta situação. Nestes casos, embora os vínculos afetivos sejam preservados ou possam ser facilmente resgatados, não são suficientes para garantir um ambiente familiar acolhedor e eliminar os conflitos. Nestas famílias, também, o retorno ao lar é um momento delicado e decisivo do processo de reinserção familiar e social dos egressos de casas de passagem.

\subsection{Principais fatores que influenciam o processo de reinserção familiar e social}

Os fatores que, segundo as famílias em estudo, contribuíram para a institucionalização da criança/adolescente, em geral, são os mesmos que influenciam no processo de reinserção familiar e social que estão vivenciando. Dentre esses, os mais referidos foram:

- Os vínculos familiares entre o egresso e outros membros: de modo geral é a qualidade dos vínculos afetivos entre pais e filhos que determina, com muito mais intensidade que outros fatores referidos, os rumos do processo de reinserção familiar. Quando estes são reconhecidos como importantes, demonstrados entre os membros da família e preservados mesmo quando esta vive em condições adversas, a reinserção ocorre de maneira mais fácil, embora necessite de suporte social e profissional para se efetivar. Este fato evidencia que o afastamento da criança/ adolescente de sua família, mesmo tendo a intenção de protegê-los, pode não ser uma decisão apropriada uma vez que pode fragilizar os vínculos entre eles;

- A configuração familiar caracterizada como monoparental: dentre as famílias em estudo, a monoparentalidade foi referida como sendo uma condição que acarreta sobrecarga em termos de cuidado e responsabilidade para um dos pais, principalmente quando o filho está na fase da adolescência;

- Situação econômica precária: embora não se possa atribuir o sucesso ou o fracasso do processo de reinserção dos egressos apenas à condição de pobreza de suas famílias, também não se pode negar seu potencial negativo, uma vez que com ela geralmente se estabelece uma cadeia de riscos que inclui, além da carência de recursos básicos para a sobrevivência, também outros como, por exemplo, a marginalização social. É nestas circunstâncias que a pobreza econômica dessas famílias vem tendo um papel crítico no processo de reinserção familiar e social de seus filhos;

- Alcoolismo e dependência de outras substâncias: na história de vida das famílias em estudo é alta a incidência de alcoolismo nos pais e dependência de drogas nos filhos, o que contribui para a instauração de conflitos e a manutenção de um ambiente familiar pouco receptivo por ocasião do retorno da criança/adolescente para o lar;

- A rede de suporte social da família: a maioria das famílias está inserida em uma rede informal de suporte social que inclui membros da família expandida (irmaõs, avós, tios, primos) e outros recursos da comunidade. Raramente os vizinhos são reconhecidos como integrantes de sua rede social, uma vez que, com estes, as relações são, em geral, conflituosas. Um dos recursos utilizados com frequência, no âmbito da comunidade, são os espaços destinados a utilidade pública nas emissoras de radio locais. Ao ser questionada a respeito dos fatores que estavam dificultando para receber o filho após a desisntitucionalização e mantê-lo no lar, uma mãe responde que: "a falta de comida não é problema porque se a gente não consegue um serviço, pede ajuda na radio, ou na assistência social". Por outro lado, a rede de serviços de saúde como postos de atendimento, hospitais, centros de atendimento psicológico e outros, são acionados apenas nas situações em que a família é obrigada a fazê-lo como condição para evitar nova interferência do Conselho Tutelar.

Estes foram os fatores mais citados pelas famílias como determinantes do rumo do processo de reinserção familiar e social das crianças/ 
adolescentes após seu desligamento da casa de passagem onde viviam. Com certeza, muitos outros influenciam nesse processo, já que os maus tratos na infância é um problema multideterminado. Entretanto, nos limites deste estudo, estes são os de maior impacto para as famílias.

\subsection{Reinserção familiar e social: um desafio para os egressos e para os profissionais}

Os resultados deste estudo mostram que os desafios inseridos no processo de reinserção familiar e social são múltiplos se levarmos em conta a grave situação de risco psicossocial em que vivem as famílias, no interior das quais se criam as condições para a intervenção dos Conselhos Tutelares. Geralmente são famílias imersas em uma situação de miséria econômica, relacional, emocional, que dificilmente é solucionada durante o período em que dura a institucionalização de seus filhos, por mais longa que esta possa ser. Estes desafios não são só para as crianças e os adolescentes que, em um determinado momento de suas vidas, foram afastados do convívio familiar e institucionalizados em abrigos para menores, mas, também, para os profissionais que trabalham com essas famílias e precisam aprender a administrar a insuficiência de recursos pessoais, familiares e contextuais e, também, o conformismo e a desesperança de muitas famílias que perdem a capacidade de se ver no futuro, em outras condições.

Especialmente com relação a precariedade da situação econômica presente em todas as famílias é importante considerar que a pobreza não é apenas uma relação das pessoas com as coisas. É, também, uma relação do ser humano consigo mesmo. É uma condição complexa, com uma dimensão abstrata que pode mutilar a auto-estima das pessoas e uma dimensão concreta que se manifesta através da acumulação de perdas que, segundo Lacourse (2002), atingem o plano do ter (renda familiar, consumo, bens, emprego), do saber reconhecido (escolarização, formação, conhecimento) e do ser (rede social, vida familiar, lazer). Estas perdas, habitualmente, contribuem para aumentar as dificuldades destas famílias para se integrarem à vida comunitária, e dificultam a utilização dos recursos da rede social que, em determinados locais são, de fato, insuficientes para atender as necessidades das famílias, principalmente no que se refere a rede de recursos formal. Em conseqüência, seus membros dificilmente são capazes de exercer o controle sobre suas vidas e se encontram, na maior parte do tempo, em uma situação de não poder, de impotência e de dependência de ajuda social.

A literatura refere que nas situações de maus tratos na infância, geralmente os pais têm dificuldades para se relacionar não apenas com seus filhos mas, também, com outras pessoas e sofrem em conseqüência disso, razão pela qual, é freqüente que mesmo existindo recursos para atender, pelo menos em parte as necessidades das famílias, como creches, trabalhadores sociais e psicólogos, estes, frequentemente, são sub utilizados. Ao mesmo tempo, os conflitos familiares e sociais contribuem, pelo menos em parte, para dificultar cada vez mais a busca dos recursos disponíveis (como os vizinhos e os serviços de saúde). Assim, é altamente provável que estas condições se repercutam de maneira negativa sobre essas famílias, gerando um nível elevado de estresse que afeta a relação pais-filhos e, consequentemente, sobre o processo de reinserção.

Os resultados mostram, ainda, que falar de reinserção familiar implica na existência de um lugar para a família morar. Neste estudo, nem todas as famílias tinham uma casa para receber o filho. Algumas dependiam da ajuda de outros membros da família o que, na maioria das vezes, se constitui no ponto de partida para novos conflitos. Nessas condições, o processo de reinserção dos egressos fica ainda mais comprometido.

Os resultados deste estudo mostram, também, que para enfrentar os inúmeros desafios que envolvem o processo de reinserção familiar e social de crianças/adolescentes egressos das casas de passagem, os profissionais que trabalham com essas famílias, necessariamente, precisam levar em consideração uma gama de situações que devem ser analisadas desde o ponto de vista histórico, buscando apreender os fatores e o processo que culminou no afastamento e, muitas vezes, no rompimento dos vínculos familiares, procurando distinguir aqueles que estão preservados e aqueles que ainda podem ser 
resgatados. Do ponto de vista social, precisam levar em conta a capacidade e a efetividade da rede social da qual a família pode obter e dar suporte ao filho que está retornando para o lar. Da mesma forma, é imprescindível considerar as macro questões políticas, econômicas, sociais, culturais que invariavelmente se repercutem sobre as famílias e determinam os rumos do processo de reinserção familiar e social.

Para concluir, os resultados deste estudo levam a questionar a própria decisão de institucionalizar as crianças e os adolescentes, uma vez que o distanciamento do lar e a possibilidade de perda dos vínculos familiares aumenta as dificuldades por ocasião do retorno para a família. Diante da afirmação de um pai dizendo que a criança/adolescente pode ser recebido como um estranho no ninho quando retorna depois de um período de institucionalização, então, é necessário, no mínimo, rever os critérios que subsidiam a decisão de separá-la de sua família.

ABSTRACT: Family and social reintegration of children and teenagers kept away from their families and institutionalized due to maltreatment, is a challenge of significant proportions. This study aims to evaluate and diagnose the present social and family status of ex-inmates in an institution in the south of Brazil, which shelters them temporarily. The subjects are families that participated in a program of family reintegration carried out by that institution during the period their children stayed there. Data were gathered through an interview and questionnaire. The results evidenced those families' status in terms of their inclusion in the job market and school; family interactions; main factors that influence favorably or unfavorably in the reintegration process they have been experiencing. Some challenges involved in the process of family and social reintegration of those temporary shelters' ex-inmates are discussed.

KEY WORDS: Nursing; Family; Violations of human rights.

\section{REFERÊNCIAS}

AZEVEDO, M.A.; GUERRA, VN (Org.). Infância e violência doméstica: fronteiras do conhecimento. São Paulo : Cortez, 1993.

BRINGIOTTI, M. I. Maltrato infantil. Madri: Miño y Dávila, 1999.

CICCHETTI, D; LYNCH, M. Failures in the expectable environment and their impact on individual development: the case of child maltreatment. In: CICCHETTI, D; COHEN, D. J. Developmental psychopathology - risk, disorder, and adaptation. New York: John Wiley, 1995. v. 2

MANCIAUX, M. (Org.). Maltraitances: mieux traiter familles et professionnels. Paris : Fleurus, 1999.

MORAIS, E. P. Enfermagem e família - evitando a negligência. Santa Maria, 1999.

SILVA, M.R.S. Projeto resiliência: estudo as trajetórias de reinserção familiar e social de crianças e adolescentes que vivem em situação de risco psicossocial em Rio Grande/RS. Rio Grande: Departamento de Enfermagem, FURG, 2003 (CNPQ/FURG. Projeto de Pesquisa/Grupo Interdisciplinar de Pesquisa e Estudos sobre Família)

SLUZKI, C. Violência familiar e violência política: implicações terapêuticas de um modelo geral. In: SCHNITMAN, D.F. Novos paradigmas, cultura e subjetividade. Porto Alegre: Artes Médicas, 1996.

ENDEREÇO DAS AUTORAS: Rua Engenheiro Alfredo Huch, 475 Centro Rio Grande/RS 96201-900 